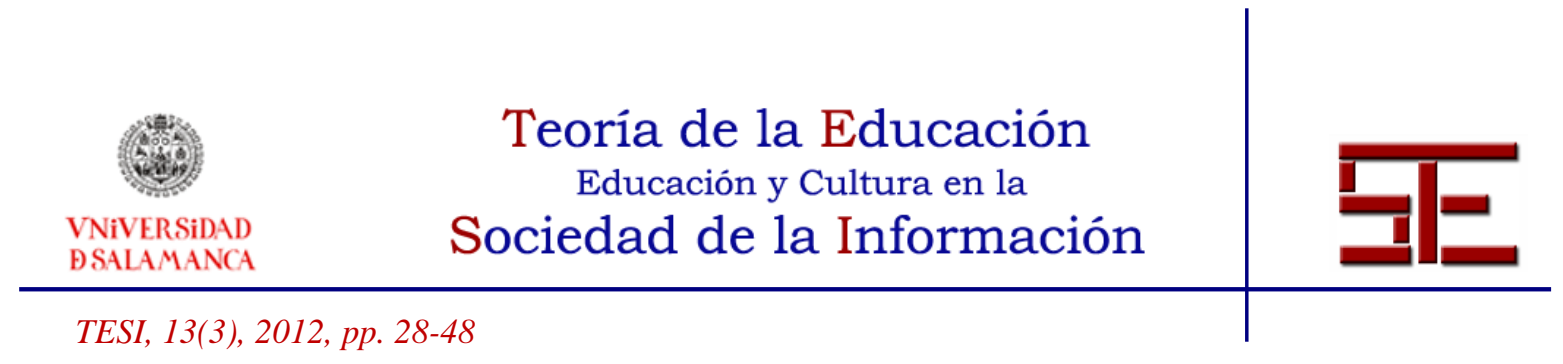

\title{
EL QUEHACER DOCENTE Y LA EDUCACIÓN EN VALORES
}

Resumen: Nuestro contexto social padece profundas deficiencias que tienen que relacionarse con lo ético. La educación se considera como una herramienta básica para superar estas deficiencias. Partiendo de lo anterior, se realizó una investigación con cincuenta docentes de nivel primaria de la ciudad de Querétaro (México) para conocer si realizaban actividades de educación en valores, el propósito que perseguían con éstas, los temas que trabajaban al respecto y las situaciones de evaluación generadas para tal fin. Los resultados muestran que los docentes dicen trabajar actividades de educación en valores; sin embargo, se observa cierta incongruencia entre el propósito que dicen perseguir y las actividades que realizan para lograrlo. Lo anterior implica que el hecho de implementar cambios curriculares no necesariamente impacta en la construcción de nuevas prácticas para mejorar los procesos educacionales. Consideramos que los resultados de este trabajo pueden ser de utilidad para los encargados de la gestión educativa pues es necesario que se realicen acciones de formación en el profesorado que contemplen no sólo la formación conceptual, sino también, la personal y valoral. Esto debería considerarse como parte del desarrollo profesional y deontológico docente.

Palabras clave: educación en valores; formación docente; maestros; convivencia escolar; educación primaria.

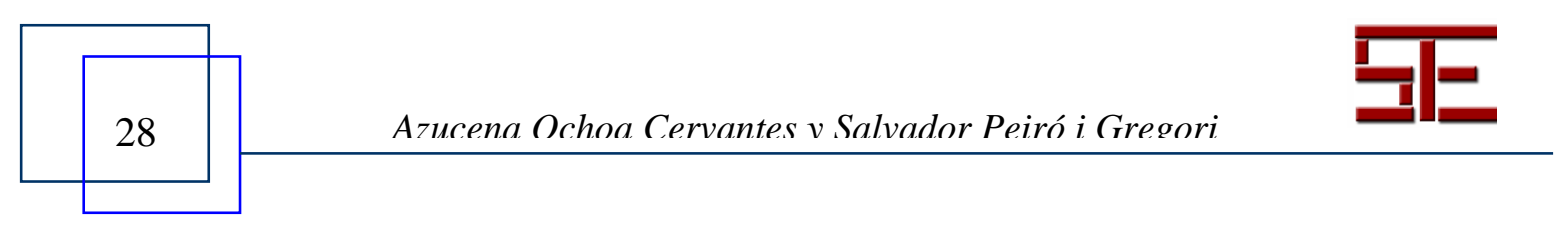




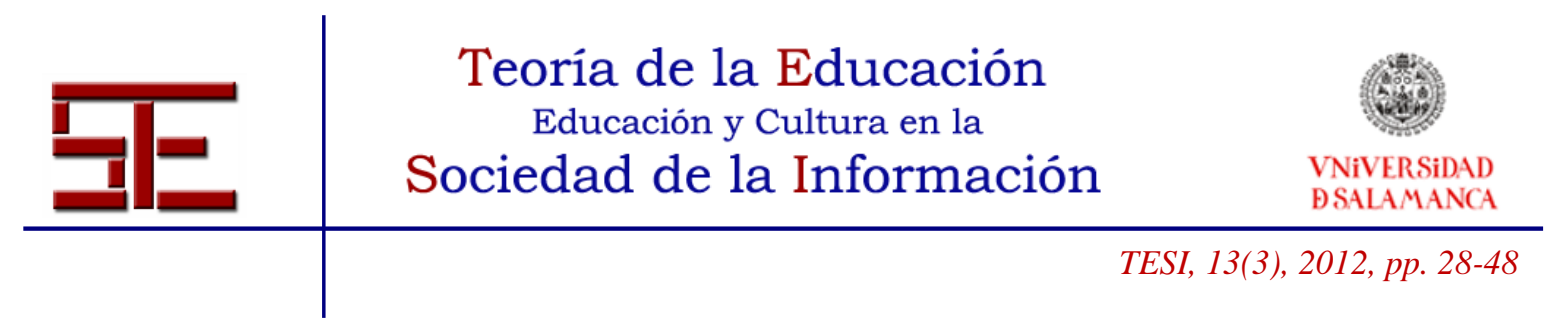

\title{
TEACHING AND VALUES EDUCATION
}

\begin{abstract}
Our social context suffers profound gaps that have to interact with the ethical dimension. Education is regarded as a one of the basic tools to overcome these shortcomings. Based of the before premise, there was conducted an research with 50 teachers from primary level of the city of Querétaro (Mexico). The aim consist on to know if carrying out education in values, the purpose pursued with these themes working thereon and assessment situations generated for that purpose. The result shows that teachers say they are working on values education. However, there is some inconsistency between the purpose pursuing that claim and the efforts to achieve this. The above said implies that the fact of to tray to implement curricular changes, it not necessarily has an impact on the construction of new practices to improve educational processes. It seems that the results of this work can be useful for policy makers of the educational management, it's because it is necessary to make training in teachers, covering not only the conceptual formation, but also the individual and the process to make values. This should be included as part of the deontological and professional development of teachers.
\end{abstract}

Keywords: values education; teacher training; school coexistence; primary education.

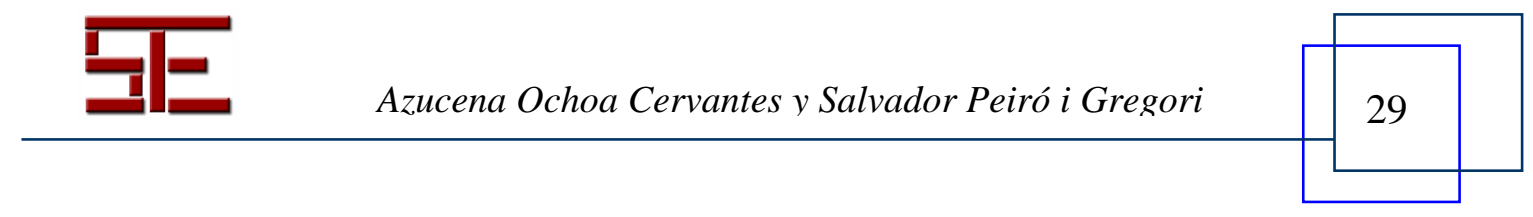




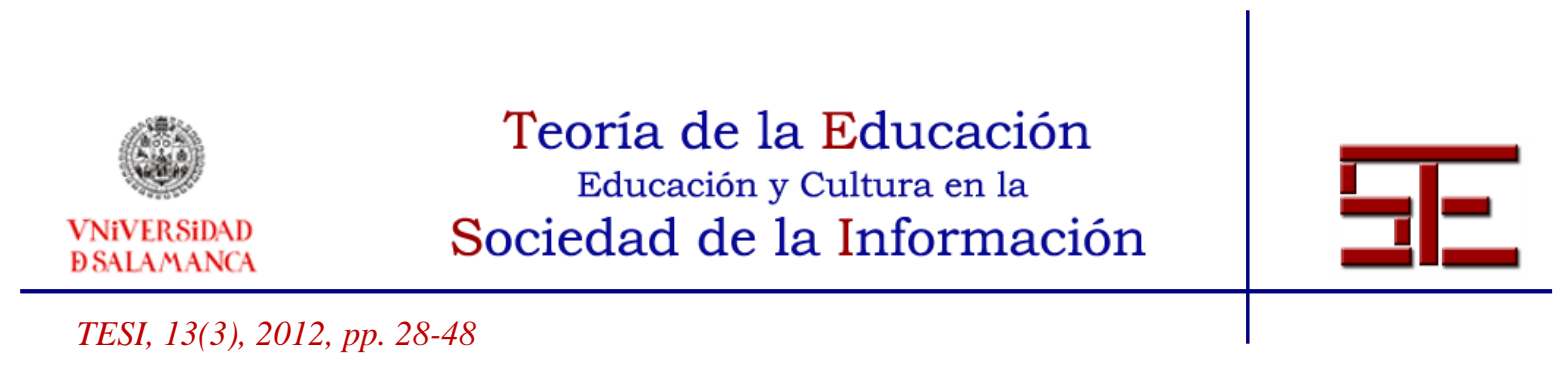

\section{EL QUEHACER DOCENTE Y LA EDUCACIÓN EN VALORES}

Fecha de recepción: 30/01/2012; fecha de aceptación: 16/05/2012; fecha de publicación: 30/11/2012

Azucena Ochoa Cervantes

azus@uaq.mx

Universidad Autónoma de Querétaro

Salvador Peiró i Gregori

peiro@ua.es

Universidad de Alicante

\section{1.- INTRODUCCIÓN}

Al final de la primera década del siglo XXI, la educación vuelve a ser considerada como un aspecto indispensable para superar los retos a los que como sociedad nos enfrentamos. El avance en los medios de comunicación e información que han distanciado cada vez más a los seres humanos, las tremendas desigualdades sociales, la pobreza extrema, la injusticia, la intolerancia, la corrupción, la impunidad y una larga lista de fenómenos producto de nuestro tiempo o, ¿de nuestra "educación"? Motivados por esta crisis, diferentes Gobiernos han asumido compromisos para responder a lo acordado en distintas instancias internacionales (ONU, UNESCO, OEI, OCDE). Uno de los primeros acuerdos lo constituye la "Declaración Mundial de Educación para Todos", celebrada en Jomtien, Tailandia, en marzo de 1990. En este documento se declara: "Que el incremento de las posibilidades de educación se traduzca en un desarrollo genuino del individuo y de la sociedad depende de que en definitiva los individuos aprendan verdaderamente como resultado de esas posibilidades, esto es, que verdaderamente adquieran conocimientos útiles, capacidad de raciocinio, aptitudes y valores" (UNESCO, 1990). Lo anterior nos hace reflexionar al respecto de lo que en la escuela se debería de promover para dar respuesta a lo reconocido en la declaración anterior. Consideramos que una de las prioridades de la educación tendría que ser la formación de actitudes y valores, debido a que aún la escuela se centra en los conceptos más que en las personas. Una escuela que responda a los planteamientos anteriores tendría que estructurarse alrededor de cuatro aspectos que Delors (1996) denomina "Los cuatro pilares de la educación". Este autor considera necesario que los individuos adquieran cuatro aprendizajes que serán esenciales para su desarrollo: aprender a conocer, aprender a hacer, aprender a vivir juntos y aprender a ser. Estos aprendizajes suponen una educación básica con un enfoque que incida no sólo en la información sino

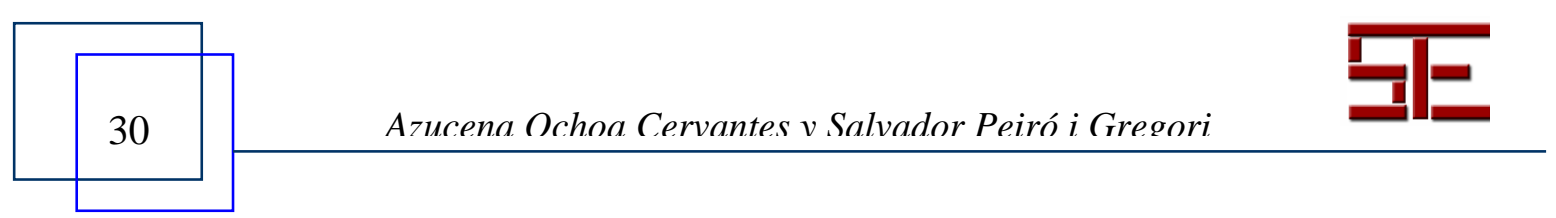




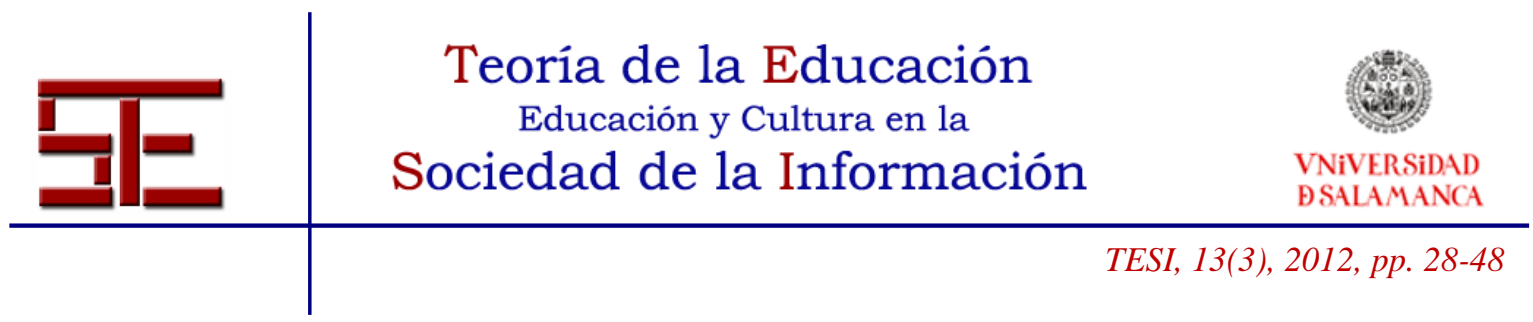

la formación de las personas, una formación básica comprometida con el desarrollo integral de los seres humanos, lo que posibilita alcanzar cada vez mayores niveles de autocontrol.

\section{1.- Importancia de la docencia en la promoción de valores}

Una de las formas de hacer explícitos los valores, que como sociedad se requieren, consiste en promoverlos a través de cambios curriculares. Partiendo de lo mencionado en las líneas anteriores, consideramos al docente como el actor que se encarga de poner en marcha el currículo. Entonces habría que reconocer su papel de mediador, que tiene consecuencias en el orden de pensar modelos apropiados de formación de profesores y en la selección de contenidos para esa formación (Gimeno, 1998: 197). La formación de los docentes es fundamental, pues son ellos quienes a través de su práctica cotidiana ponen en marcha o no los cambios planteados.

Aunado a lo anterior, es sumamente importante considerar lo que Ezpeleta (2004) señala al respecto de la apropiación de nuevas concepciones. La autora sugiere que la construcción de nuevas prácticas es un proceso difícil, fragmentado, lento, pero posible a partir de la aceptación de algunas nociones que se van ensayando o incorporando según se compruebe que funcionan y que no siempre están precedidas de una clara comprensión conceptual.

Si partimos de la idea de que el profesor no es un mero ejecutor del currículum, sino que es una persona que decide, piensa y siente en relación con las situaciones de enseñanza, se ha de tener en cuenta su formación en torno a la puesta en práctica del currículum.

Con el fin de concretar esta premisa, habría que tener presentes las propuestas de la cuadragésima sexta Conferencia Mundial de Educación "La educación para todos para aprender a vivir juntos: "Contenidos y estrategias de aprendizaje, problemas y soluciones", organizada por la UNESCO y celebrada en Ginebra en septiembre del 2001. En ésta se delinearon algunas acciones que los Gobiernos deberían emprender, entre ellas se encuentran:

- Facilitar una participación genuina de los docentes en la toma de decisiones en la escuela mediante la formación y otros medios.

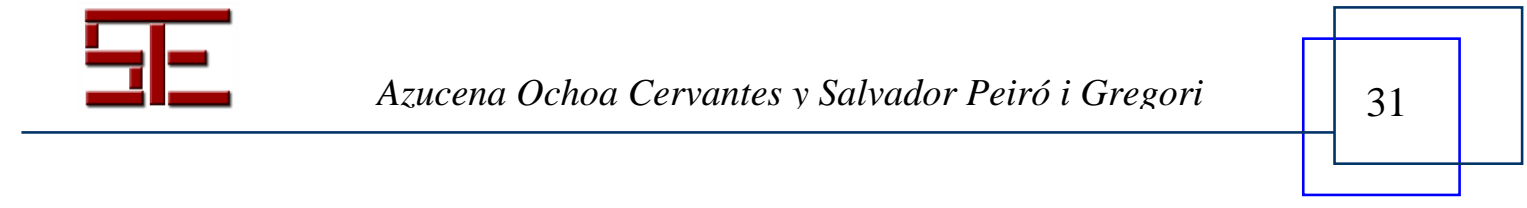




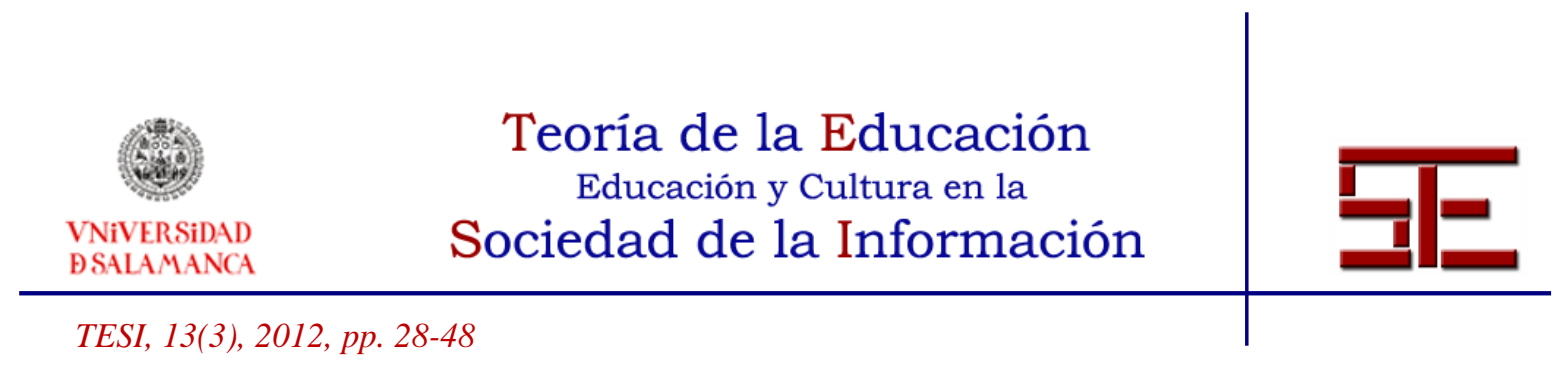

- Mejorar la formación de los docentes para que puedan desarrollar mejor en sus alumnos y alumnas los comportamientos y valores de la solidaridad y la tolerancia, preparándolos para prevenir y resolver conflictos pacíficamente, y para respetar la diversidad cultural.

- Modificar las relaciones entre el docente y alumnos y alumnas para responder al cambio de la sociedad (UNESCO, 2001).

La formación que desde nuestro punto de vista se debería promover es con respecto a la educación en valores. Siguiendo a Martínez (2001), educar en valores implica promover condiciones para aprender a construir los propios sistemas de valores, éstos se construyen a partir de los valores que nos rodean y que podemos dar cuenta de ellos por medio de las interacciones sociales que se dan en los diferentes espacios de educación: formales, no formales o informales. Esto hace que la escuela y el docente no sean las únicas fuentes de referencia para la construcción de valores; sin embargo, consideramos que aún siguen siendo fuentes de gran incidencia para la educación de los futuros ciudadanos.

Cabe señalar que ninguna educación es aséptica, es decir, implícita o explícitamente transmite valores. En este sentido, de acuerdo con Ortega (2001) cuando se habla de educación, necesariamente se habla de valores a "algo valioso que queremos que se produzca en los educandos" (p. 14).

Educar en valores implica crear condiciones para estimar los valores que permitan el desarrollo de conocimientos, habilidades y actitudes propias para la convivencia pacífica. A saber, los valores consagrados en las sociedades plurales y democráticas son lo que se denomina educación moral (Buxarrais, et al., 2001), la cual pretende aproximar a los niños y jóvenes a conductas y hábitos coherentes con los principios y normas.

En el caso particular que nos ocupa, hemos de mencionar los plasmados explícitamente en el plan de estudios de la educación básica mexicana, y, en particular, en la asignatura de "Formación cívica y ética". Tales son: respeto, justicia, igualdad, solidaridad y aprecio por la diversidad. Para lograrlo, es importante guiar la labor docente a la comprensión de la dimensión individual (desarrollo de la autonomía personal, el cultivo de la voluntad y el desarrollo emocional de la persona) y de la dimensión social (cultivo de habilidades como el diálogo, aprecio por el conflicto como posibilidad de

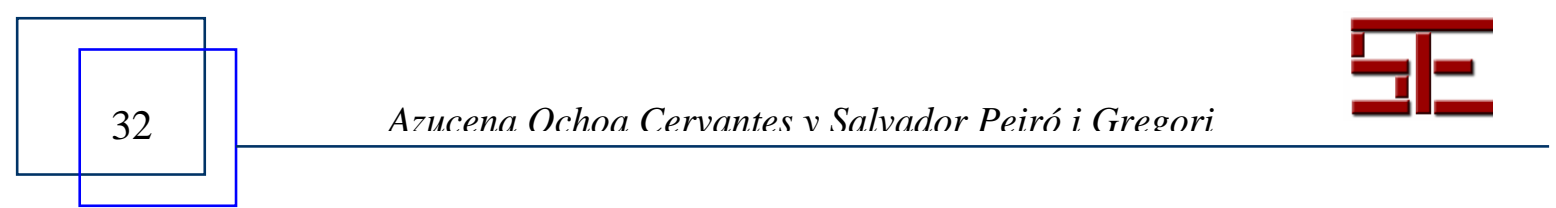




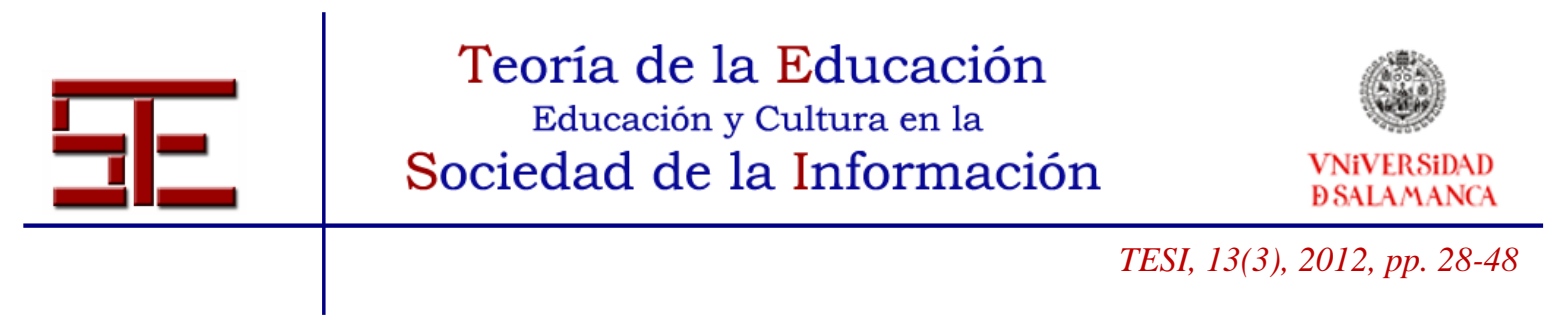

aprendizaje, la negociación y la regulación del bien común) de la formación cívica y ética. En consecuencia, es necesario que la formación de profesores esté orientada a la reflexión y análisis sobre estas dimensiones, así como de la formación ética y cívica del propio docente, pues "la importancia de que los profesores sean capaces de promover el desarrollo social y personal de los alumnos supone que ellos mismos dispongan de ese saber y que puedan llegar a ser referentes morales de sus alumnos" (Marchesi, 2008: 31). El mismo autor nos sugiere las competencias profesionales que el docente debería desarrollar: A) "Ser competente para favorecer el deseo de saber de los alumnos y para ampliar sus conocimientos", esto implicaría comprometer a los alumnos con su aprendizaje, responder a la diversidad, incorporar la lectura en la actividad educadora y ser capaz de incorporar las TIC en el aula. B) "Estar preparado para velar por el desarrollo afectivo de los alumnos y por la convivencia escolar", en este caso atender el desarrollo emocional de los alumnos, estar atento a las relaciones sociales que establecen los alumnos, manejo adecuado de comportamientos disruptivos, favorecer la participación de los alumnos, coherencia en la aplicación de normas. C) "Ser capaz de promover la autonomía moral de los alumnos", esto es, reconocer la dimensión cognitiva, afectiva y social del desarrollo moral, ser ejemplo ético ante sus alumnos. D) "Ser capaz de desarrollar una educación multicultural", reconocer la identidad cultural de los alumnos. E) "Estar preparado para cooperar con la familia", ser capaces de manejarse con eficacia en la colaboración con los padres, colaboración entre profesores para establecer acuerdos. F) "Poder trabajar en colaboración y en equipo con los compañeros", éste se considera el primer paso para una actividad equilibrada y eficaz.

En suma, es necesario promover lo que Buxarrais, et al., (2001) denominan educación moral, pues lo que se pretende es que la reflexión individual de los principios y normas interiorizadas por los niños y jóvenes, se vea reflejada en sus formas de conducirse. Es decir, no se pretende una imposición de normas y valores sino que, a lo que se aspiraría es a promover que los niños y jóvenes sean capaces de orientarse de manera autónoma ante situaciones que supongan un conflicto de valores, evitando el riesgo de caer en prácticas individualistas a través del diálogo y el acuerdo con los demás. Esto implica reconocer, como se había planteado en líneas arriba, una doble dimensión de la educación en valores (educación moral), la comprensión de la dimensión individual (desarrollo de la autonomía personal, el cultivo de la voluntad y el desarrollo emocional de la persona) y de la dimensión social (cultivo de habilidades como el diálogo, aprecio por el conflicto como posibilidad de aprendizaje, la negociación, la participación y la regulación del bien común). Por lo anterior, resulta importante la formación docente en

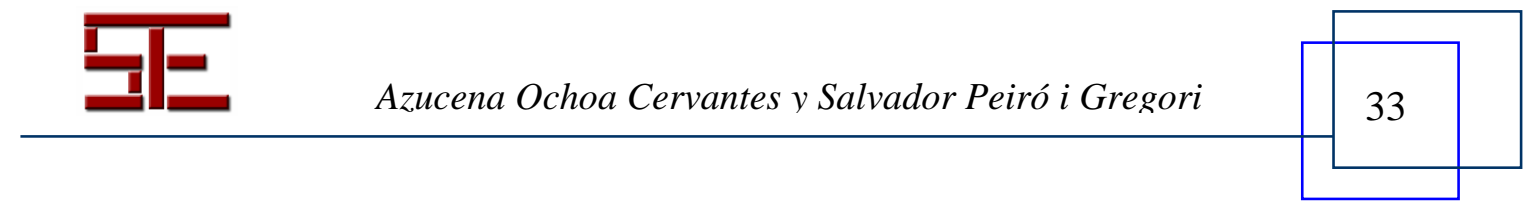




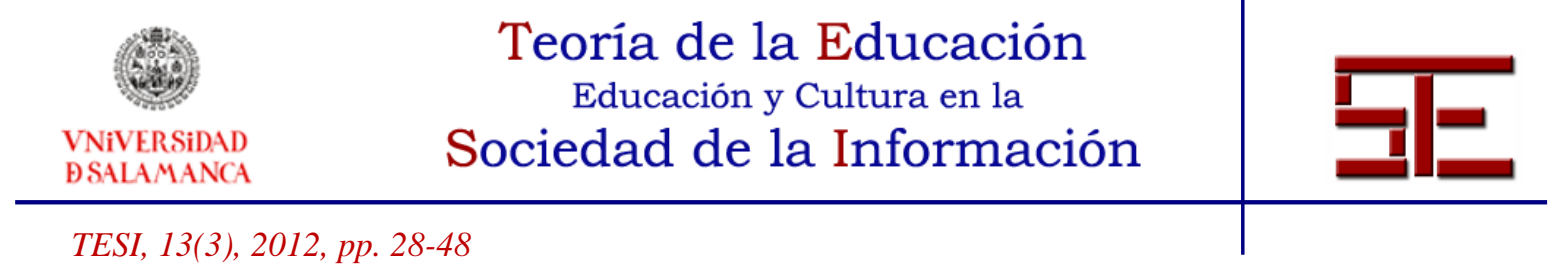

cuanto al desarrollo cognitivo y emocional de los niños y jóvenes, así como de estrategias para concretar en el currículum la educación en valores.

La misma autora expone las capacidades que se espera que el profesor desarrolle ante la responsabilidad de educar en valores, a saber: capacidad de crear un clima escolar adecuado, capacidad de crear situaciones que plantean problemas y contradicciones, capacidad de escuchar, aconsejar y ayudar en la formación, capacidad para construir un modelo teórico propio y adaptado a la situación educativa concreta, capacidad de animar a los grupos y analizar su funcionamiento, capacidad de trabajo sobre su propia persona, capacidad de tender hacia la naturalidad pedagógica, capacidad de diseñar actividades particulares tendentes al desarrollo de la autoconfianza del educando, capacidad para poseer un autoconcepto ajustado y positivo, capacidad para afrontar situaciones potencialmente conflictivas (Buxarrais, 2003).

Lo anterior nos lleva a centrar la mirada en el profesor como protagonista, es necesaria una formación inicial y permanente que le permita desarrollar las competencias pedagógicas para enfrentar los nuevos retos que la educación plantea. Esto genera en nosotros algunas interrogantes: ¿los maestros realizan actividades de educación en valores?, ¿qué propósitos persiguen?, ¿qué estrategias utilizan para alcanzar dichos propósitos?, ¿hay congruencia entre estos elementos?

\section{2.- BREVE ESTADO DE LA CUESTIÓN}

En México no abundan los estudios específicos $\mathrm{y}$, sobre todo, experiencias generalizables en materia de "educación en valores", o como lo menciona la UNESCO para "aprender a vivir juntos". En el 2001, Hirsch y Quezada realizaron una investigación documental acerca del estado de conocimiento que guardaba el tópico de educación y valores de 1990 al 2001. Las autoras analizaron quince reportes de investigación, de los cuales la mayoría se centró en la investigación de valores cívicos; el concepto Estado-nación es el referente más significativo en la enseñanza de valores. Por su enfoque disciplinario, se clasificaron nueve categorías como sociológicas, tres ubicables dentro de la psicología social, dos en el marco educativo-etnográfico y uno correspondiente a la historia. Los temas sobre los que versaron las investigaciones revisadas fueron: identidad del mexicano, símbolos patrios, valores nacionales, valores cívicos y morales que debe transmitir la escuela. Las autoras concluyen que dado el

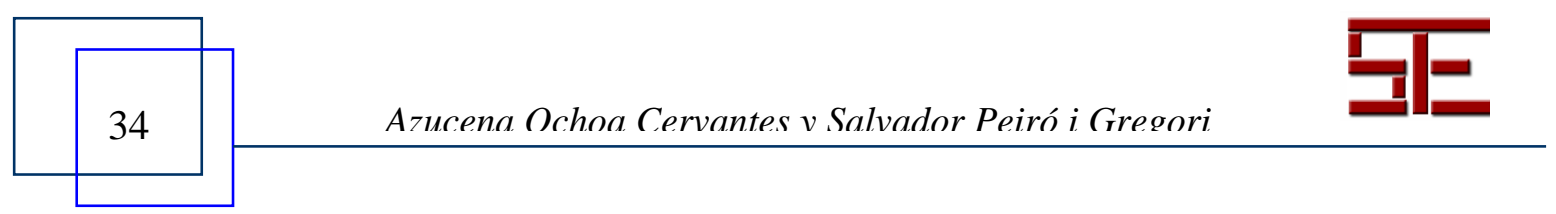




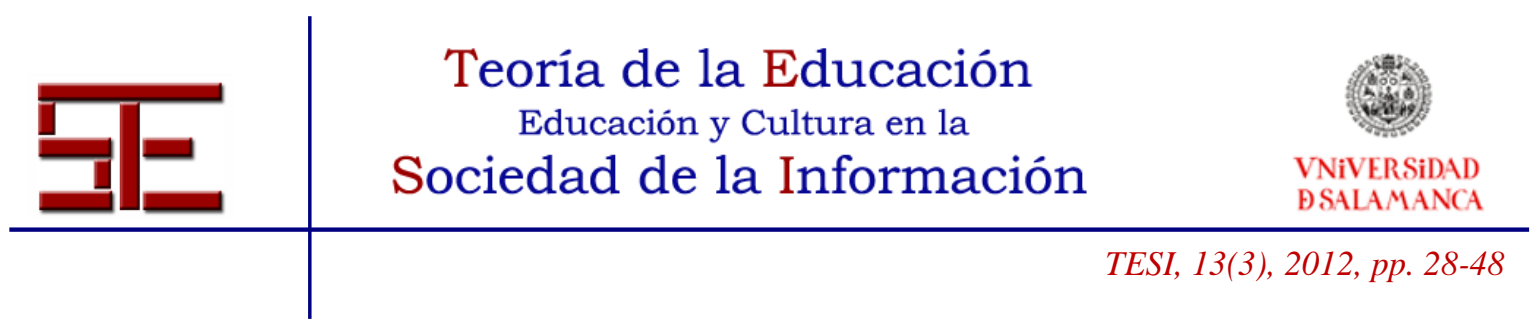

estado de conocimiento encontrado es necesario profundizar en el tema, sobre todo lo que se refiere a los valores que transmite el aparato escolar.

Por su parte, Fierro y Carbajal (2003) realizaron una investigación etnográfica que pretendía responder las siguientes interrogantes: si toda práctica docente transmite valores, aun sin proponérselo ¿cómo ocurre esto a través de las interacciones cotidianas?, ¿cómo se pueden hacer "visibles" los valores que el docente transmite en su práctica cotidiana?, ¿por medio de qué mecanismos o procesos se produce dicha transmisión en la escuela? Los principales hallazgos de las autoras se centran en lo que denominaron "la oferta valoral del docente", en donde concluyen que la transmisión de valores se da mediante el comportamiento normativo, el afectivo y la conducción de procesos de enseñanza. Para las autoras los valores están anclados en la forma como se trabaja en el aula, instalado en las declaraciones y normas que se plantean a los alumnos, así como en la consistencia con que se hacen cumplir; en el tipo de trato que se da a los alumnos, los vehículos que se utilizan y los juicios de valor. Estas conclusiones confirman lo que ya otros autores han descrito acerca de la educación en valores (Camps, 1994).

Araujo-Olivera et al. (2005) analizan los valores que influyen en la formación para la asignatura "Formación cívica y ética", en estudiantes de secundaria del estado de Morelos, a partir de entrevistas, observaciones y cuestionarios. Los autores concluyen que el respeto es conceptualizado por los adolescentes desde lo prescrito socialmente y consiste en no lesionar los intereses de otros. Con respecto a la democracia, eluden el conflicto asociado con la política, se adscriben a una democracia que impida la aparición de éste y que propicie la "sujeción para la paz". A pesar de que la democracia es deseable, no conciben la posibilidad del disenso y está desvinculada del ejercicio político de la ciudadanía. Según la autora, en sus discursos se revela la representación de una democracia prescriptiva o ideal que, lejos de contribuir a confrontar lo que es con lo que debiera ser procurado, se muestra como un horizonte que, por inalcanzable, alimenta la desesperanza y el fatalismo.

Por su parte, Matías Romo (2005) realizó la investigación denominada "Desarrollo del juicio moral en bachilleres de Aguascalientes". En esta investigación se muestra el juicio moral basado en la teoría del desarrollo moral de Kohlberg, utilizando el instrumento Defining Issues Test (DIT) de James Rest. Los resultados que presenta el autor fueron que el nivel de razonamiento predominante fue convencional; en moralidad postconvencional se obtuvieron puntuaciones por debajo de otros estudios. Relacionada

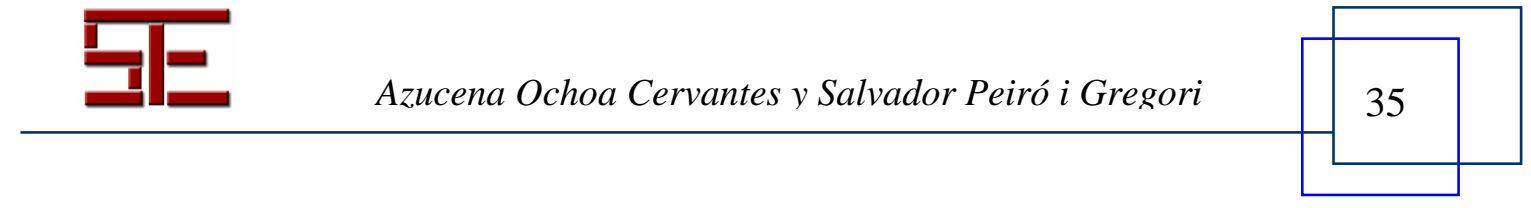




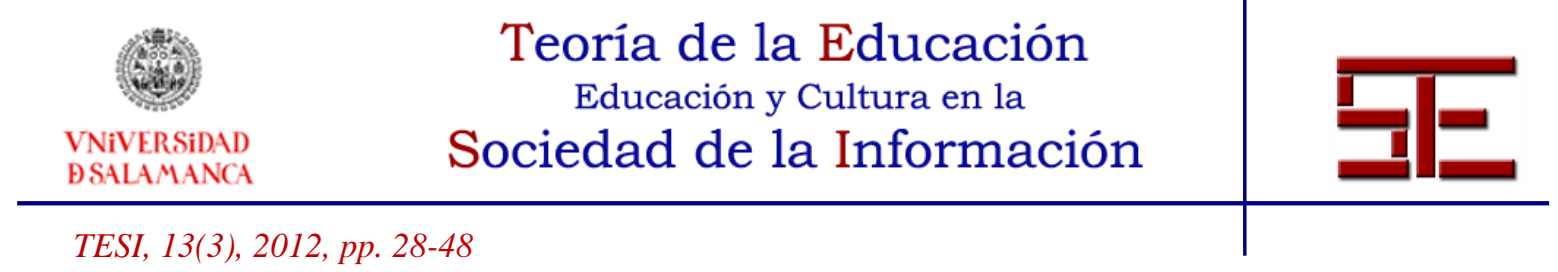

con la investigación anterior, el mismo autor junto con Barba, (2005) presentan la investigación "Desarrollo del juicio moral en la educación superior", los autores presentan una evaluación del desarrollo moral de estudiantes de educación superior con base en la teoría de L. Kohlberg. Se analiza su perfil moral según las siguientes variables: semestre, género, institución, carrera, edad y nivel educativo. Los principales resultados son: el nivel de moralidad predominante es el convencional; las mujeres de una institución privada aventajan a los hombres en la moralidad de principios; sólo en tres instituciones los estudiantes de semestres avanzados logran un desarrollo moral mayor que los de primero; las carreras con mayor ventaja son Filosofía y Derecho y las de menor, Mantenimiento industrial y Procesos de producción; las instituciones con mayor avance moral son una normal privada y una universidad pública y las de menor, una universidad tecnológica y un instituto tecnológico agropecuario.

El Instituto Nacional para la Evaluación en Educación (INNE) realizó una investigación denominada "Disciplina, violencia y consumo de sustancias nocivas para la salud en escuelas primarias y secundarias de México" (Aguilera, Muñoz y Orozco, 2007). El estudio estuvo conformado por dos acercamientos, uno a través de los datos recabados por los exámenes de la calidad y logro educativo, que se aplicaron a alumnos y a docentes de educación primaria, y otro en el que se realizó un acercamiento cualitativo a través de entrevistas con alumnos y docentes de veinte centros secundarios para describir su funcionamiento, organización y problemáticas. Entre los hallazgos más importantes hay que destacar que la magnitud de la violencia manifestada por los estudiantes es relativamente baja. Por último, hay una diferencia de opinión entre alumnos y profesores en cuanto a los problemas de convivencia entre estudiantes. Por un lado, los maestros tienden a minimizarlo y, por otro lado, los alumnos perciben que los maestros no los atienden sobre todo cuando se trata de acciones que pudieran parecer leves, como las burlas.

Como puede observarse en los estudios descritos se indaga sobre la violencia en las escuelas, sobre el desarrollo del juicio moral en jóvenes y sobre los valores cívicos centrados en el concepto Estado-nación. Son pocos los estudios que hacen referencia a las formas en que el docente educa en valores. Ya desde 1998, Schmelkes apuntaba que existe una urgente necesidad de formación teórica, pues a pesar de que la teoría que podría considerarse como más sólida es la del juicio moral, no hay evidencia empírica suficiente. La misma autora apunta que experimentalmente es muy conveniente desarrollar procesos que permitan ir descubriendo formas metodológicas que favorezcan la apropiación crítica y autónoma de valores. Porque, si bien los valores son

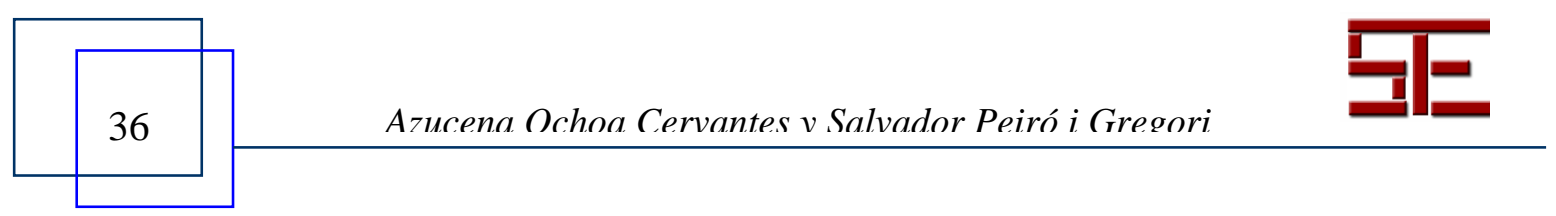




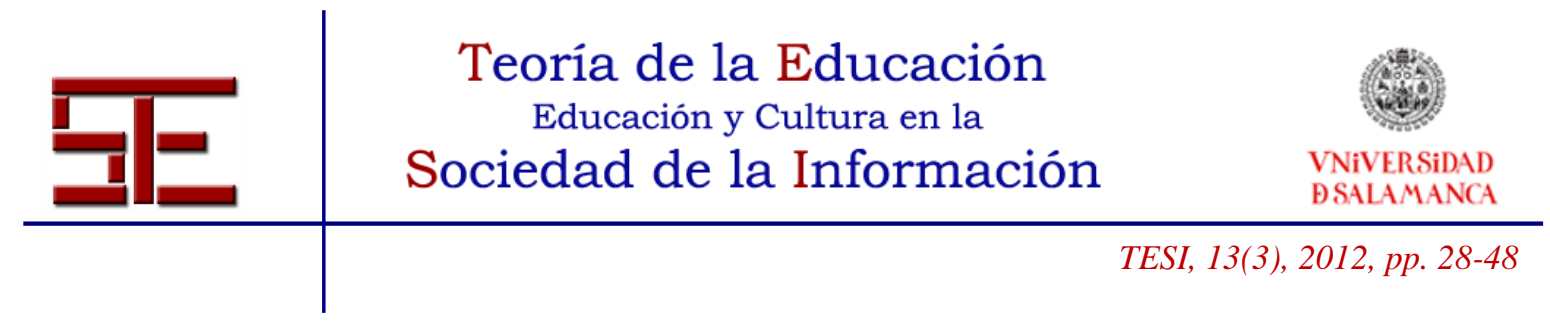

construidos inicialmente a nivel personal, el proceso para llegar a la definición es necesariamente social e involucra análisis, reflexión, planteamientos de alternativas, revisión de consecuencias, etc. Esto nos lleva a pensar que los docentes deberían estar formados en los aspectos individuales, sociales y didácticos de la educación en valores. Apoyándonos en la exposición anterior y con el fin de conocer el estado de la cuestión referido en las premisas anteriores, nos formulamos las siguientes interrogantes: ¿los docentes realizan actividades de educación en valores?, ¿cuál es el propósito que persiguen?, ¿cuentan con las estrategias pertinentes?, ¿las aplican?, ¿cómo?, ¿son sistemáticas?, etc.

\section{ESTUDIO DE CASO EN QUERÉTARO (MÉXICO)}

Para tratar de responder las interrogantes anteriores, se realizó una investigación con el objetivo de indagar qué acciones puntuales realizan los docentes de educación primaria de la ciudad de Querétaro en relación con la educación en valores.

3.1. Metodología.A partir de análisis de documentos y fenomenología de docentes, integrando informes de investigaciones y experiencias, en el año 2000 se confeccionó un cuestionario (http://violencia.dste.ua.es). Luego, con el fin de describir la realidad, se partió de un diseño exploratorio descriptivo, utilizando técnicas cuantitativas para la recolección de los datos.

\subsection{Objetivos}

a) Conocer si los docentes realizan actividades relacionadas con la educación en valores.

b) Indagar qué aspectos de la educación en valores dicen trabajar.

c) Mostrar las situaciones que dicen generar para trabajar la educación en valores.

d) Conocer los aspectos que toman en cuenta para evaluar este ámbito, así como los instrumentos que emplean.

3.3. Población. Se trabajó con 54 docentes de nivel primaria de la ciudad de Querétaro (México). Las escuelas de donde procedían los docentes pertenecían al sector público y estaban ubicadas en un contexto urbano. La selección de los docentes fue aleatoria y el criterio que la guió fue la disposición del director y los docentes para acceder a contestar el instrumento.

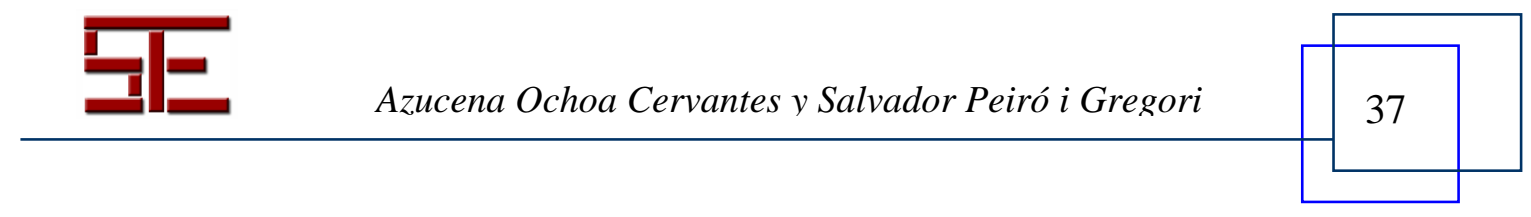




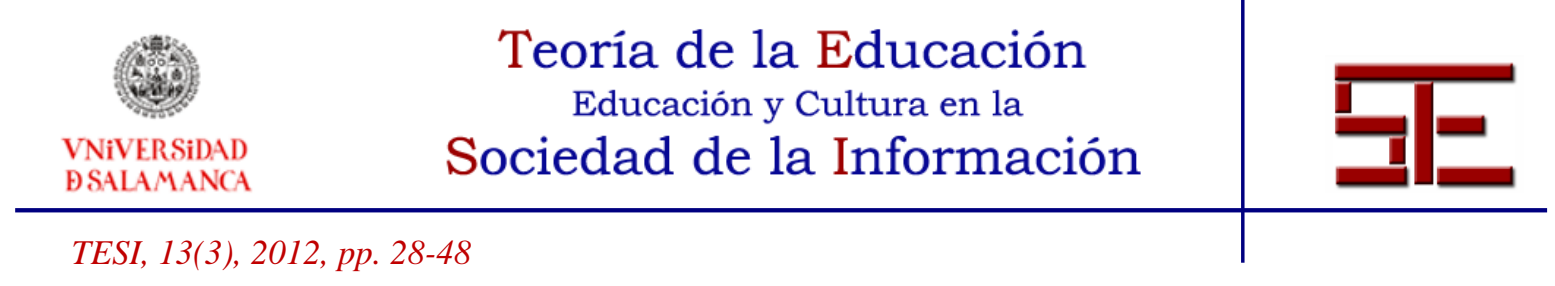

3.4. Instrumento. Se aplicó el citado cuestionario que contenía 12 reactivos ${ }^{1}$. Estuvo diseñado de tal forma que pretendía conocer si se realizaban o no actividades de educación en valores, qué tipo de actividades se generaban, cuál era el objetivo, si eran programadas o no, las capacidades y habilidades que para el docente era importante desarrollar y el tipo de evaluación que realizaban. Todos los reactivos tenían las respuestas predeterminadas, por lo cual, los docentes elegían la que consideraban que reflejaba su práctica en relación con la educación en valores. Este cuestionario se aplicó durante los meses de marzo, abril y mayo del 2009 (ciclo escolar 2008-2009).

3.5. Procedimiento. Los cuestionarios fueron entregados personalmente a los docentes, quienes lo respondieron en el momento y, una vez complementado, fue regresado al investigador. Una vez aplicados los cuestionarios, se procedió a organizar la información en la base de datos ex profeso para ello. Posteriormente se obtuvieron las frecuencias de respuesta de cada reactivo y se calcularon porcentajes para conocer la proporción en cada una.

\section{RESULTADOS, INFERENCIAS Y DISCUSIÓN}

Una vez obtenidos los porcentajes se organizaron en tablas y gráficos en donde se presentan los resultados que se observan a continuación. En el Gráfico 1 se observan las respuestas acerca de la pregunta, ¿realiza actividades de educación en valores?

Gráfico 1. Porcentaje de frecuencia de respuestas a la pregunta ¿realiza en su aula alguna actividad relacionada con la educación en valores?

${ }^{1}$ El mencionado cuestionario puede consultarse en el sitio web http://violencia.dste.ua.es, dentro de la solapa "cuestionarios", abriendo la sección "estudio de la violencia escolar", y para acceder escribir como clave: p_estudio. Ésta sólo sirve como acción consultiva y no operativa.

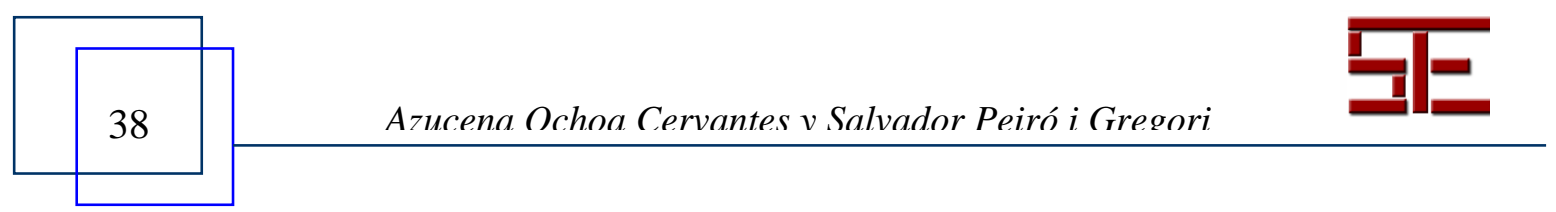



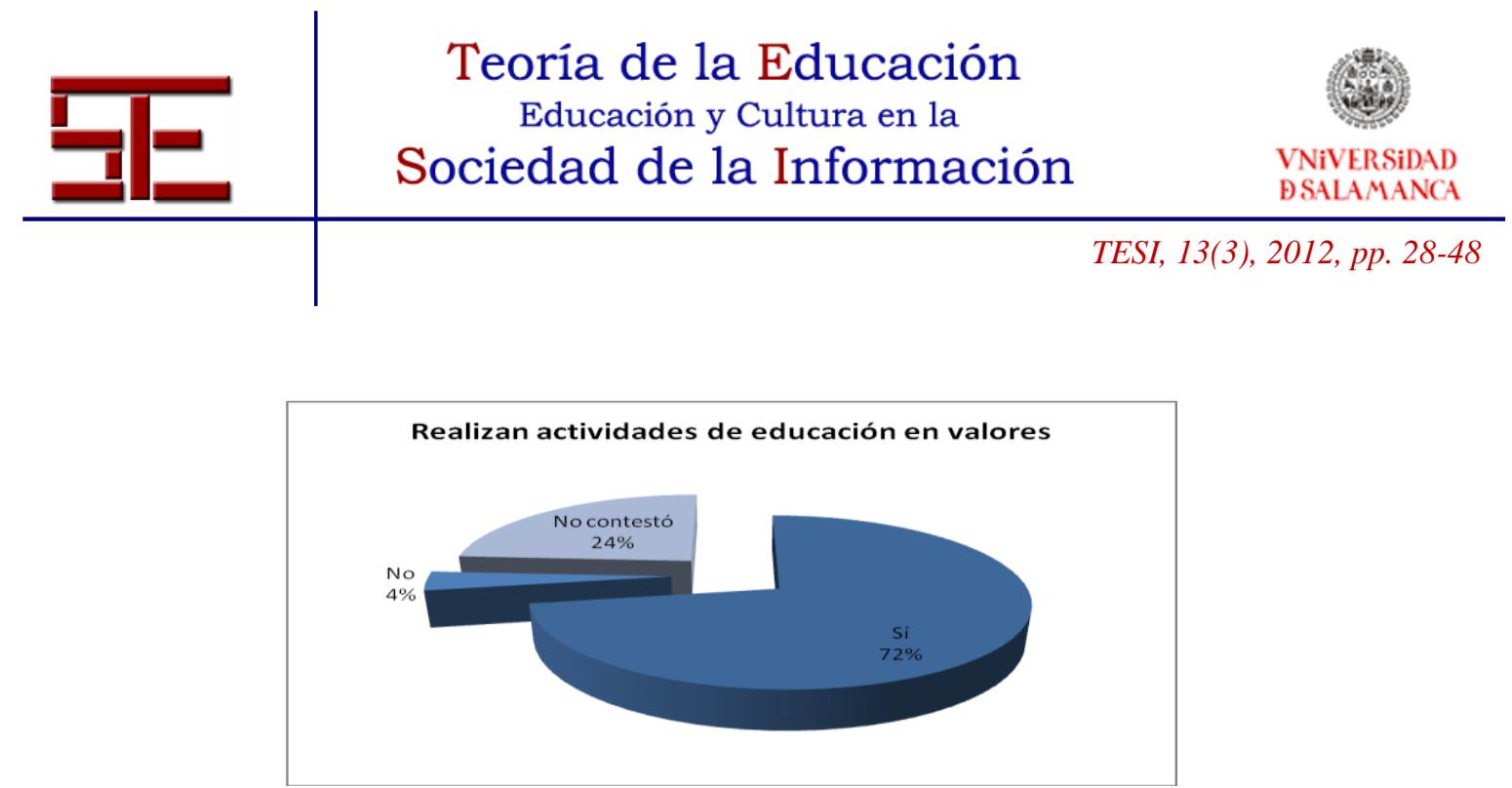

Como se observa, el $72 \%$ dice realizar actividades de educación en valores, el 4\% contestó no realizar este tipo de actividades y el $24 \%$ no contestó.

También se les preguntó al respecto de por qué no se realizan estas actividades. En la Tabla A se observan las respuestas.

Tabla A. Porcentaje de frecuencia de respuestas a la pregunta ¿por qué no se desarrollan estas actividades?

\begin{tabular}{|l|c|}
\hline \multicolumn{1}{|c|}{ Respuestas } & Porcentajes \\
\hline Por falta de propuestas de actividades concretas & 25.9 \\
\hline Por no disponer de tiempo & 25.9 \\
\hline Por falta de coordinación de los profesores & 22.2 \\
\hline Por falta de formación del profesorado & 7.4 \\
\hline Porque no se contempla en el proyecto escolar & 5.5 \\
\hline
\end{tabular}

Para profundizar en las actividades que realizan, se les preguntó acerca del tipo de situaciones que generan para trabajar esas actividades. En el Gráfico 2 se observan las respuestas. Si consideramos que los docentes son piezas claves para promover los cambios curriculares que se requieren para una formación integral. Podemos observar que si bien sólo es el $4 \%$ de los maestros los que dicen no realizar actividades específicas, es importante considerar las respuestas que dan al respecto pues podemos observar en éstas la problemática que viven y a la que se enfrentan cotidianamente en sus espacios, como puede ser la falta de tiempo, la falta de coordinación o la falta de un proyecto común que les permita trabajar en conjunto.

Tabla B. Porcentaje de frecuencia de respuestas acerca de las situaciones generadas por los docentes para realizar actividades de educación en valores

\begin{tabular}{|l|l|}
\hline Situación generada & Porcentaje \\
\hline
\end{tabular}

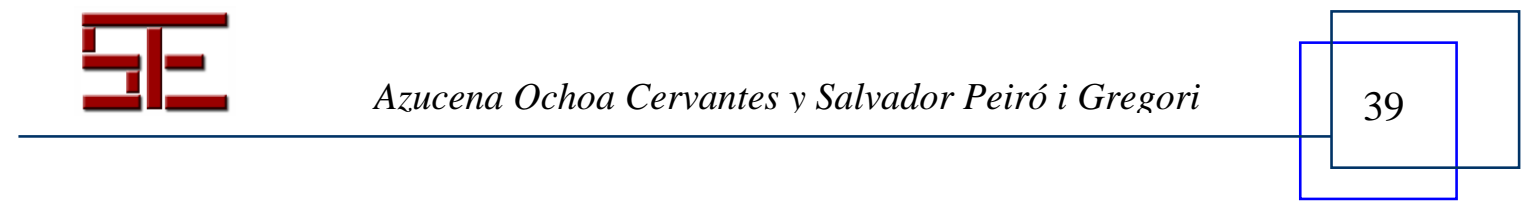




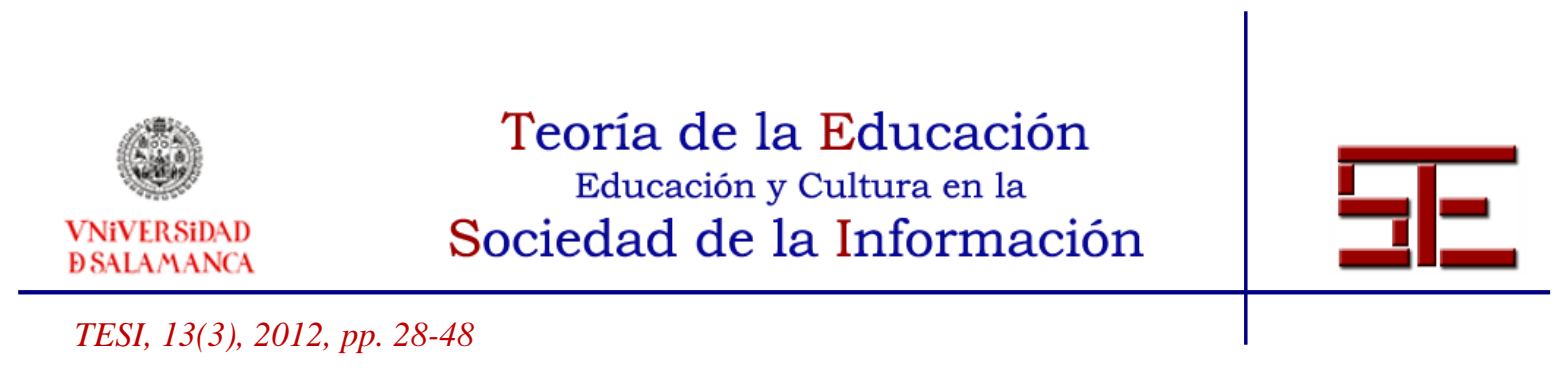

\begin{tabular}{|l|l|}
\hline Lecciones de valores & 87 \\
\hline Enseñanza de actitudes & 85 \\
\hline Clarificación de valores & 78 \\
\hline Razonamiento moral & 78 \\
\hline Debates & 67 \\
\hline Formación del carácter & 63 \\
\hline Actividades culturales & 55 \\
\hline Dilemas & 55 \\
\hline Representación de roles & 52 \\
\hline Asambleas & 44 \\
\hline Celebraciones & 31 \\
\hline Filosofía para niños & 20 \\
\hline
\end{tabular}

Las respuestas con mayores porcentajes fueron las que se refieren a "lecciones de valores" (87\%) y "enseñanza de actitudes" (85\%). Llaman la atención estas respuestas debido a que educación en valores no es aleccionar o adoctrinar, por lo que este resultado nos sugiere profundizar en ello para conocer a qué se refieren los docentes o qué es lo que hacen cuando dan lecciones de valores o enseñan actitudes, pues estas situaciones, en el caso de los valores, no aseguran el desarrollo de la reflexión que se requiere para construir el sistema de valores a los que las sociedades democráticas aspiran.

Las siguientes situaciones mencionadas por los docentes fueron "clarificación de valores" y "razonamiento moral", ambas con 78\%. Es importante mencionar que estas situaciones si bien son de gran utilidad para desarrollar el juicio moral, no aseguran la acción moral, es decir, que es importante realizar este tipo de actividades con los niños, sin embargo, es necesario no limitarse a éstas debido a que se correría el riesgo de que los niños pudieran reflexionar y emitir juicios al respecto de ciertas situaciones pero no actuar en consecuencia.

También contamos con cuestiones que hacen referencia a "el debate" (67\%). Esta estrategia resulta fundamental para promover las capacidades de diálogo, negociación y tolerancia, sin embargo, habría que profundizar en la forma de utilizarlo pues es importante recordar que de lo que se trata es de ayudar a los alumnos a construir su sistema de valores y, con esto, promover el cambio de actitudes y conductas. Las respuestas que se presentaron con un menor porcentaje fueron asambleas (44\%), celebraciones como el día de la paz (31\%) y filosofía para niños $(20 \%)$. Es interesante resaltar que una de las estrategias fundamentales de participación son las asambleas, esto sugiere que la educación en valores no sólo se debe procurar con actividades "de

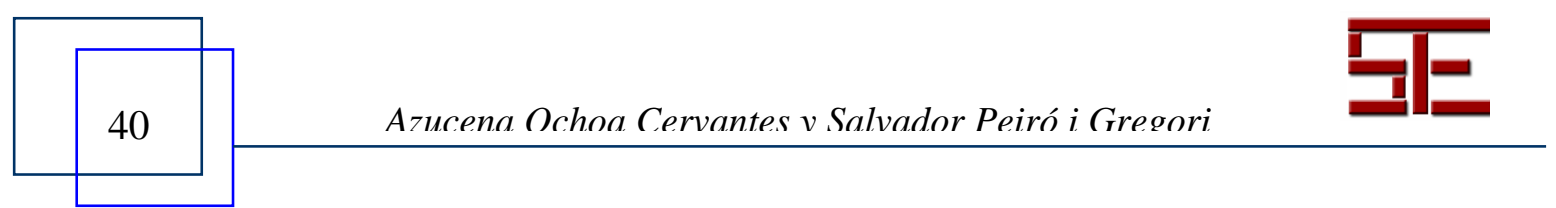




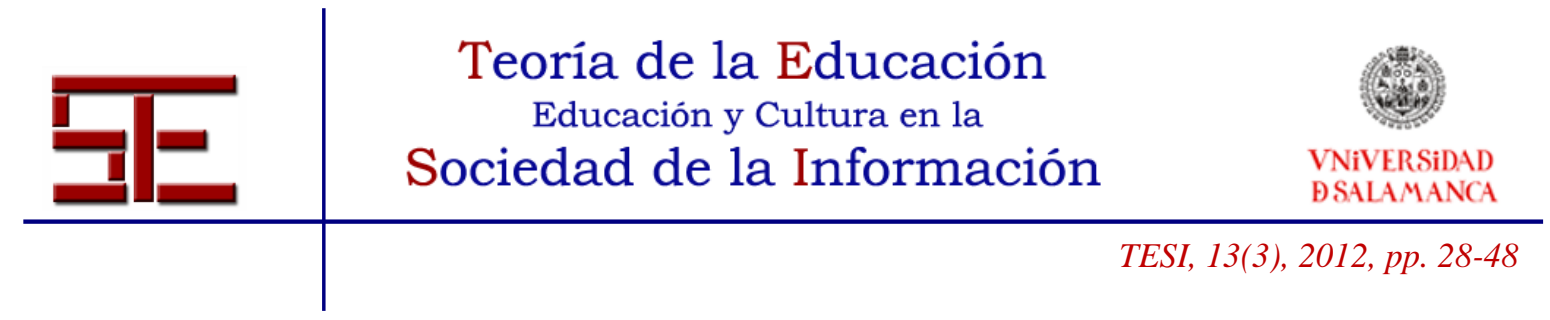

clase" sino con otro tipo de actividades que permita a los alumnos vivenciar los valores, como en el caso de las asambleas.

Para complementar lo anterior, en el cuestionario había la posibilidad de escribir alguna otra opción, algunos docentes dieron sus respuestas, las cuales se muestran en la tabla C.

Tabla C. Porcentaje de frecuencia de respuestas de otras actividades realizadas.

\begin{tabular}{|l|c|}
\hline Actividad & Porcentaje \\
\hline Calendario de valores & 5.5 \\
\hline Lecturas destacando un valor & 5.5 \\
\hline Juegos & 5.5 \\
\hline Cuentos & 5.5 \\
\hline Hablo con los niños & 3.7 \\
\hline Significado del valor & 3.7 \\
\hline El valor del mes & 3.7 \\
\hline
\end{tabular}

Podemos inferir a partir de estas respuestas y de las inmediatas anteriores que algunos docentes mantienen una postura enciclopedista en relación con la educación en valores pues actividades como las mencionadas no promueven la reflexión, el análisis y menos aún el cambio de actitudes. A continuación se les cuestionó acerca del propósito que perseguían al realizar actividades de educación en valores. En el Gráfico 2 se pueden observar las respuestas.

Gráfico 2. Porcentaje de frecuencia de respuesta acerca del propósito que persiguen los docentes al realizar actividades de educación en valores

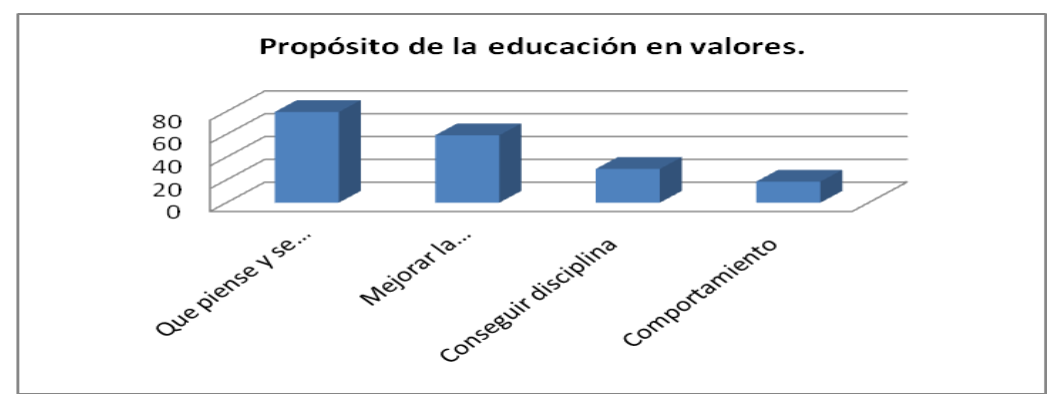

Como se observa en el Gráfico 2, la mayor proporción de las respuestas se concentra en la respuesta de "Motivar al alumnado para que piense, exprese y pueda decidir" (79.6\%). Esta respuesta resultaría un tanto contradictoria en relación con las actividades

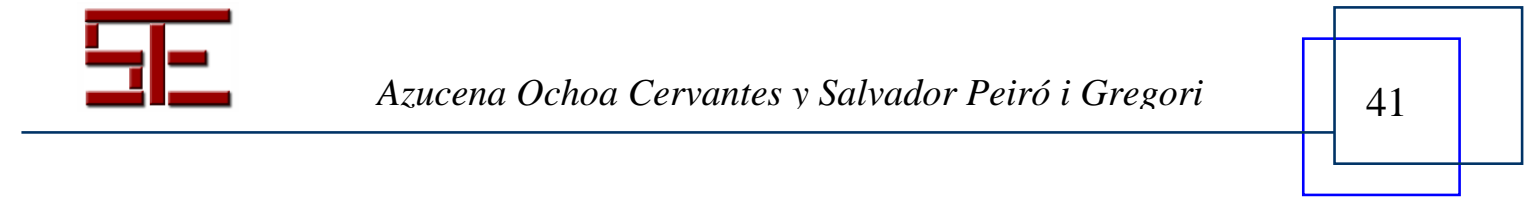




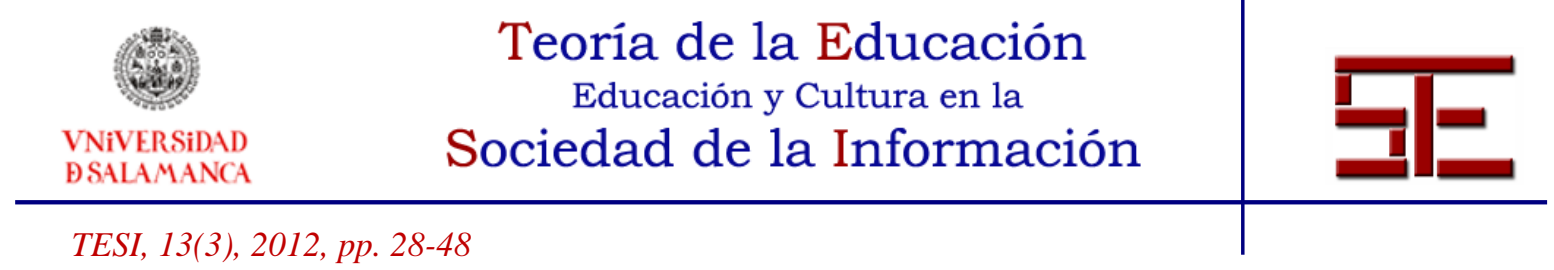

que se generan, pues si la mayor proporción de respuestas se concentran en lecciones de valores, enseñanza de actitudes, razonamiento moral y clarificación de valores ¿cómo se lograría que los alumnos pasaran del pensamiento a la acción?

La siguiente respuesta es la de "mejorar la convivencia en el aula" (59.2\%), "mejorar la disciplina" (29.6\%), "incidir en el comportamiento del alumno" (18.5\%). Si bien la "enseñanza" de valores implicaría una mejora en el clima de convivencia en los centros escolares, las respuestas nos sugieren la preocupación de los docentes por mantener el "control" dentro de sus aulas. Sería necesario confirmar la afirmación anterior con estudios en donde se indague acerca de las ideas de los maestros acerca de la disciplina, así como de las actitudes que desean cambiar o favorecer en el alumnado.

Para profundizar acerca de lo que los profesores dicen realizar, se les cuestionó acerca de los temas que trabajan o han trabajado en relación con la educación en valores.

Gráfico 3. Porcentaje de frecuencia de respuestas acerca de los temas trabajados por los profesores de los tres niveles educativos en los dos grupos

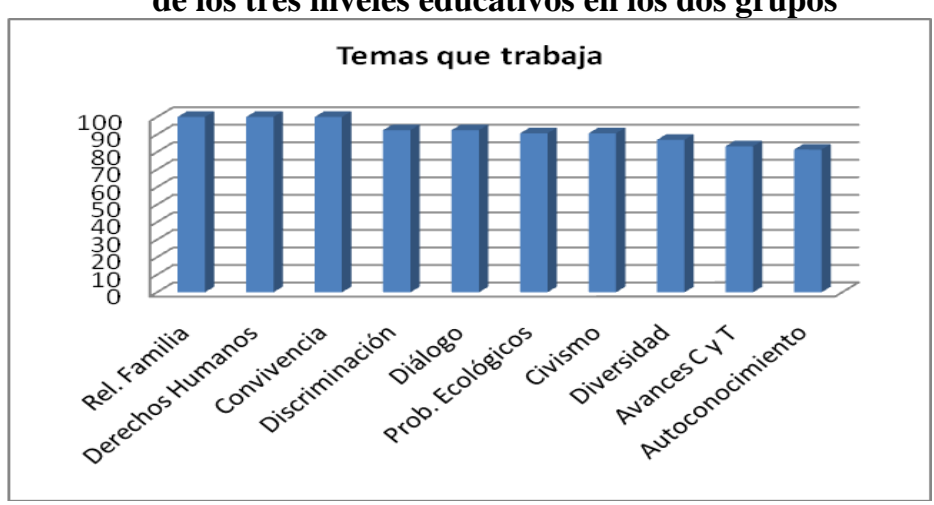

Llama la atención que los temas "relaciones con la familia", "derechos humanos" y "convivencia" dicen ser trabajados por el $100 \%$ de los docentes. Estos resultados son alentadores y podrían indicarnos que los docentes han asumido la tarea de educación en valores que de manera explícita se deberían trabajar en la asignatura "formación cívica y ética".

Para conocer la modalidad que emplean para trabajar las actividades de educación en valores se les acerca de la forma en que trabajan estos temas. En el Gráfico 4 se observan las respuestas: se practica más del doble la transdisciplinariedad (70\%) que la docencia por asignaturas (30\%).

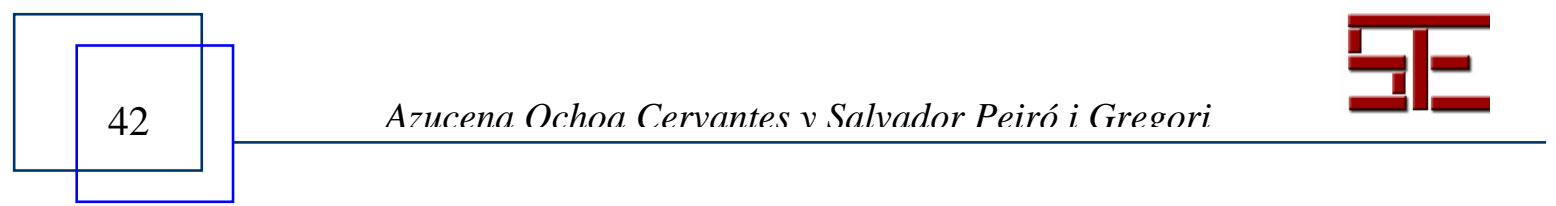




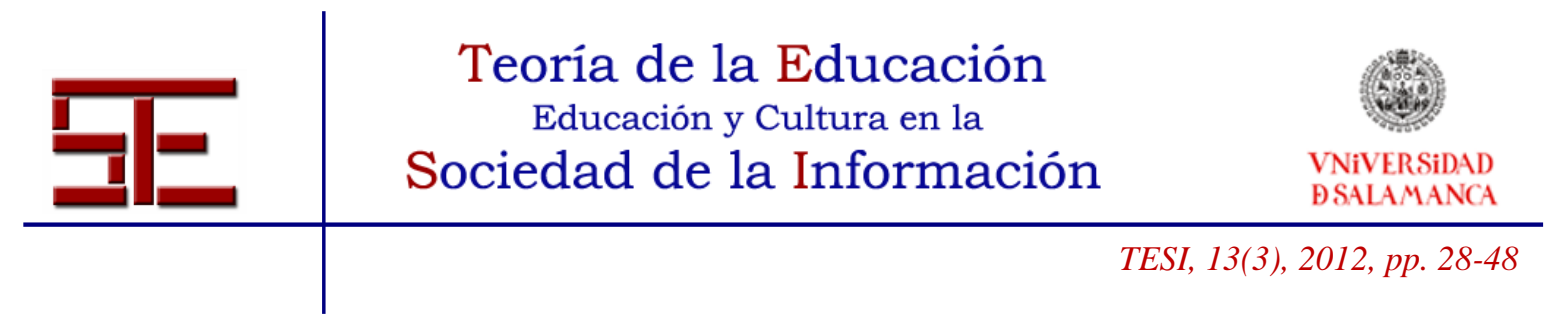

Gráfico 4. Porcentaje de frecuencia de respuestas acerca de la modalidad de trabajo de las actividades de educación en valores

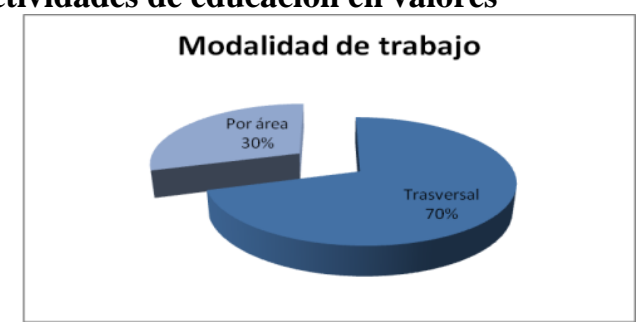

Como puede observarse, el $70 \%$ afirma trabajarlas en forma transversal mientras que el $30 \%$ afirma hacerlo como un área específica. Resultaría interesante profundizar en esta respuesta, debido a que los docentes de este nivel se enfrentan a un cambio curricular en donde se les pide, a través de la asignatura de formación cívica y ética, el tratamiento de valores específicos esto implicaría el trabajo de estas actividades como un área específica pues exigiría el despliegue de estrategias específicas. Por otra parte, existen temas de gran relevancia social que implicarían un trabajo transversal.

Para conocer la forma en que evalúan las actividades relacionadas con los valores, se les preguntó acerca de los aspectos que toman en cuenta para realizar la evaluación. En el Gráfico 5 se pueden observar las respuestas.

Gráfico 5. Porcentaje de frecuencias de respuestas al reactivo: Según su opinión, ¿cuáles son los aspectos en que se debe centrar la evaluación?

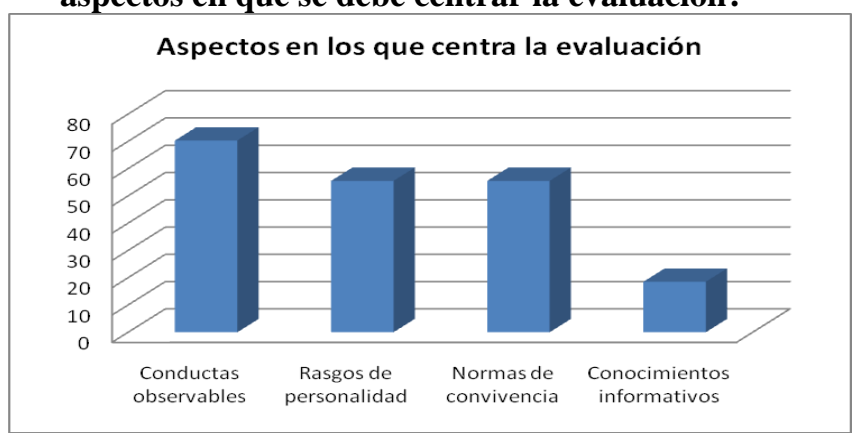

El $70.3 \%$ de los docentes opina que la evaluación debe centrarse en conductas observables, relacionado con lo anterior, el 55.5\% manifiesta que se debe centrar en los rasgos de personalidad. Con el mismo porcentaje los que opinan que debe centrase en

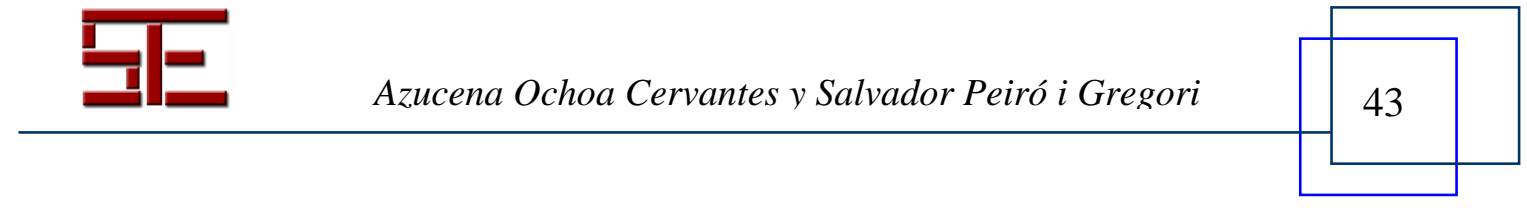




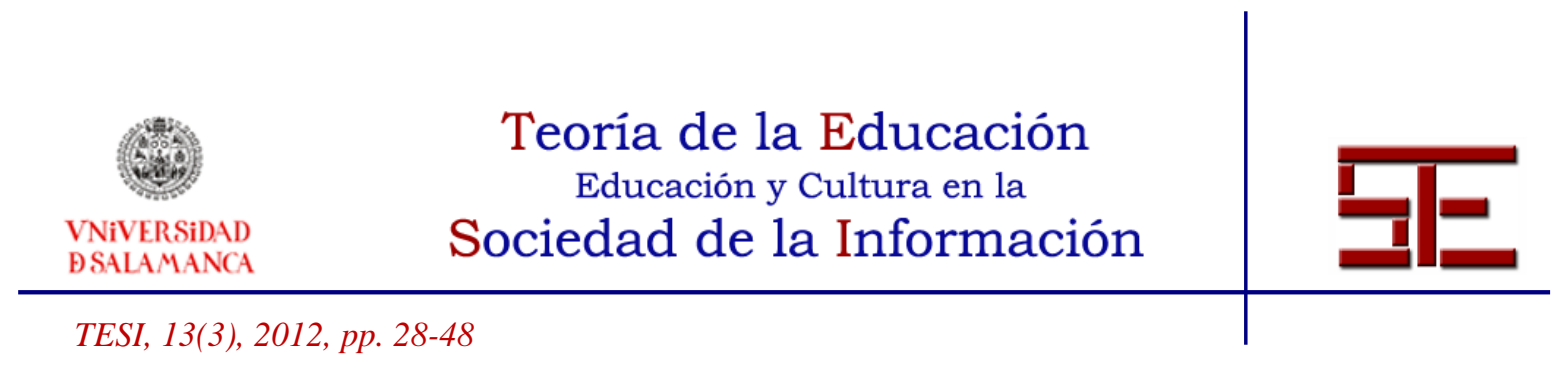

normas de convivencia, mientras que el $18.5 \%$ dice que en los conocimientos informativos.

A partir de las respuestas podemos inferir que los docentes se basan en lo que observan para evaluar, es decir, en los rasgos de personalidad, en las conductas observables y en el cumplimiento de las normas de convivencia. Si bien es importante valorar los cambios de conducta o la modificación de actitudes, es importante que exista claridad y congruencia entre lo que el maestro evalúa y lo que el alumno manifiesta, pues como se ha mostrado en algunos estudios (Marchesi, et al., 2005; Aguilera, et al., 2007) en ocasiones las percepciones de los profesores y los alumnos no coinciden y esto puede generar conflictos.

De estos resultados, con relación a los anteriores, encontramos bastante coherencia. La razón es que las metas establecidas giran en torno al logro del autocontrol y no sólo forzar para que logren el dominio axiológico de sí mismos.

Para profundizar en lo anterior se les preguntó acerca de los instrumentos que utilizaban para evaluar. En el Gráfico 6 se observan las respuestas.

Gráfico 6. Porcentaje de frecuencia de respuesta acerca de los instrumentos que utiliza el docente para evaluar las actividades de educación en valores

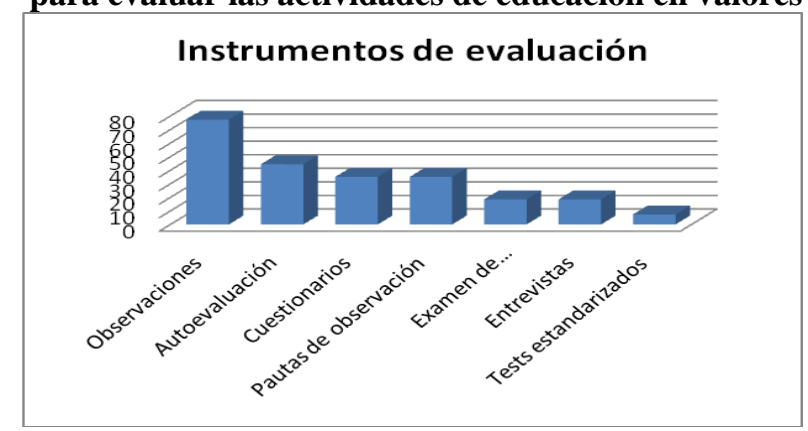

Se observa una cierta congruencia entre lo que dicen evaluar y los instrumentos que utilizan para hacerlo, pues los docentes dicen tomar en cuenta las conductas observables y los instrumentos que dicen utilizar en mayor proporción (observaciones 77.3\%). Sin embargo, llama la atención que una proporción de profesores diga utilizar cuestionarios, examen de conocimientos y, más aún, que digan utilizar test estandarizados. Entonces tenemos cierta incongruencia con relación a la anterior consideración, en cuanto que esta manera de proceder desdice lo relativo a los fines educativos: no parece que haya tanto acento en el logro del autocontrol. Es importante recordar que una de las

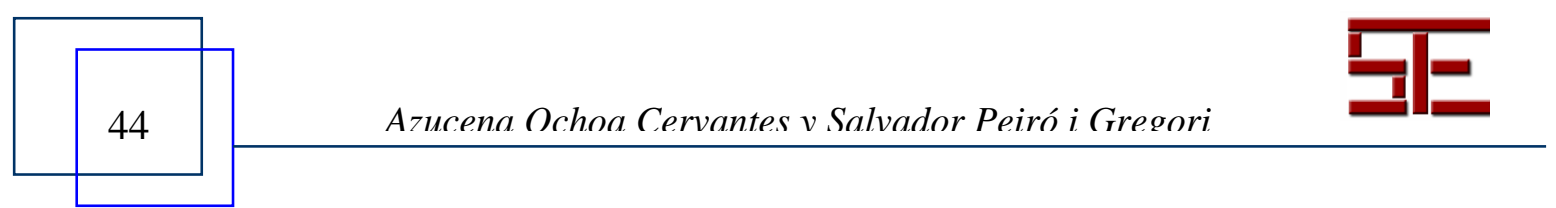




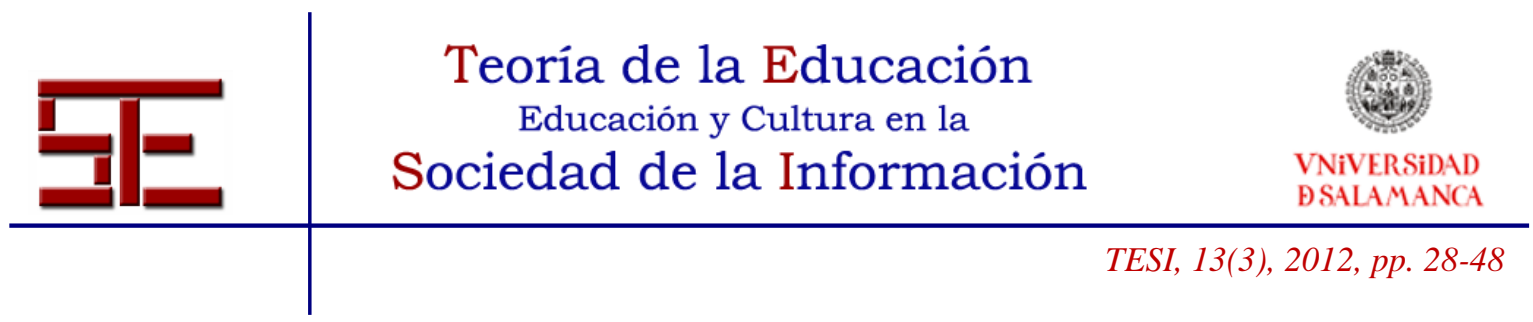

dificultades de la evaluación cuando se trabajan actividades de educación en valores es la falta de precisión si las observaciones que se realizan son parciales, asistemáticas y sin criterios definidos.

\section{DISCUSIÓN Y CONCLUSIONES}

1) A partir de los resultados del presente estudio se puede afirmar que la mayoría de los docentes que participaron realiza actividades de educación en valores y éstas tienen como propósito que el alumno piense, se exprese y aprenda a decidir; es decir, promover la autonomía moral de los estudiantes. Sin embargo, se observa cierta incongruencia entre el propósito que dicen perseguir y las actividades que dicen hacer para lograrlo. Esto se puede explicar inicialmente por la reciente introducción de la materia de "Formación cívica y ética" en donde se le solicita al docente que trabajen de manera sistemática actividades de educación en valores.

2) Lo anterior nos lleva a concluir que la construcción de nuevas prácticas es un proceso difícil, fragmentado y lento, que se realiza a partir de la aceptación de algunas nociones que se van ensayando o incorporando según se compruebe que funcionan y que no siempre están precedidas de una clara comprensión conceptual.

3) Consideramos la necesidad de formación docente al respecto de las situaciones didácticas que los docentes deberían promover, pues en los resultados se muestra una postura "enciclopedista" de la educación en valores. Por lo que se sugiere formación al respecto de las estrategias metodológicas de la educación en valores, específicamente de valores para la convivencia.

4) Es fundamental reconocer el papel del docente como mediador del currículum. Pues, de acuerdo a los resultados, los valores están anclados a la forma "enciclopédica" de la enseñanza, marcados sólo mediante normas, siendo dudoso incluso en las formas que los reglamentos se hacen cumplir. Por esto, sería importante que los docentes y los encargados de la formación inicial y permanente de los mismos reflexionaran al respecto de lo "que no se ve" de los valores y la necesidad de lograr hábitos en comunidades concretas.

5) En la formación inicial y perfeccionamiento de los docentes en ejercicio, no sólo habría que introducir técnicas y sistemas de enseñanza y evaluación. El aspirante a la docencia y el profesor en activo deberían aprender los fundamentos antropológicos y

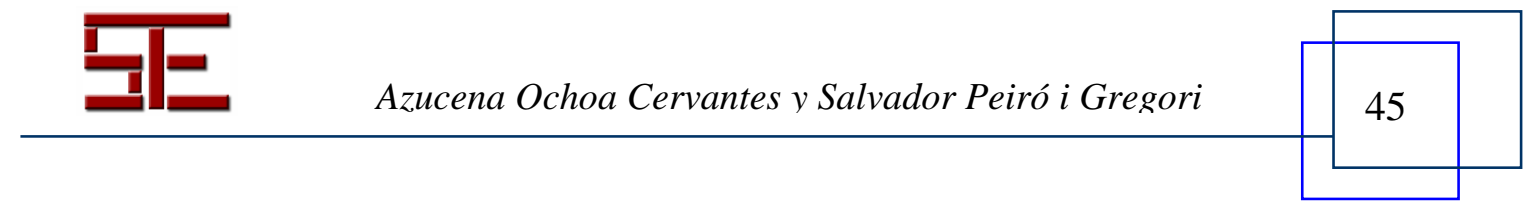




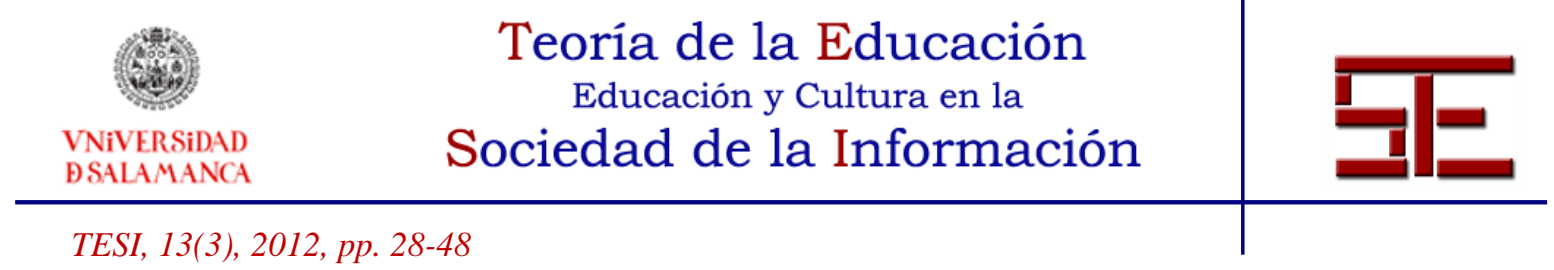

axiológicos para saber ubicar los valores y los hábitos en los procesos de educación, a fin de evitar lagunas, como la confusión del saber con el actuar. Esto es decisivo para el logro de la madurez y el desenvolvimiento en una vida cívica en libertad.

6) No sugerimos que los docentes sean los únicos responsables de la promoción de los valores personales de los estudiantes. Es necesario que las instancias responsables de la formación inicial y permanente de los docentes asuman la responsabilidad que corresponde para proporcionar los elementos básicos para lograr los objetivos que se desprenden de las anteriores conclusiones.

7) Es necesario recalcar también que, si bien la escuela es un espacio privilegiado de formación, las familias también deben retomar la responsabilidad que les corresponde a este respecto, la formación de los niños y jóvenes no es un asunto menor, es una responsabilidad de los Gobiernos y las sociedades en general. Por esto, la "comunidad educativa" es un modelo que debe establecerse, a fin de lograr que cada alumno pudiera llegar a su ética máxima (jerarquía personal de valores).

8) Los aportes de esta investigación se centran en la necesidad de conocer los discursos y las prácticas docentes, para que, una vez conociéndolas se inicie con un cambio de actitudes y modos de pensar la educación.

Estamos ciertos que toda práctica educativa conlleva valores, por lo tanto, una de las limitaciones de este estudio es el no haber observado la práctica de los profesores pues los valores están implícitos no sólo en los discursos sino en las prácticas. En este sentido, se sugiere para futuras investigaciones un estudio cualitativo para observar la "enseñanza" de los valores a través de la interacción cotidiana entre los miembros de la comunidad escolar y, con esto, conocer los aciertos y desaciertos de la enseñanza para plantear sugerencias en cuanto a la formación inicial y permanente de los profesores.

\section{BIBLIOGRAFÍA}

Aguilera, A., Muñoz, G. y Orozco, A. (2007). Disciplina, violencia y consumo de sustancias nocivas a la salud en primarias y secundarias. Publicación del Instituto Nacional para la Evaluación de la Educación. Extraido el 12 de enero de 2010, de: http://www.inee.edu.mx/images/stories/Publicaciones/Recursosyprocesos/Disciplina/Pa rtes/disciplina06.pdf.

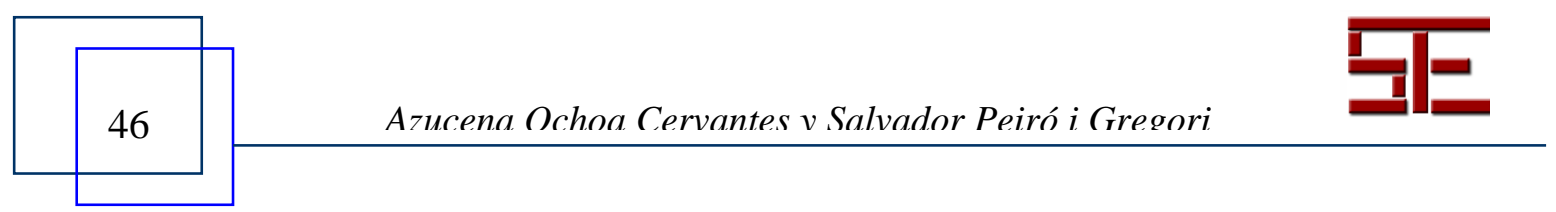




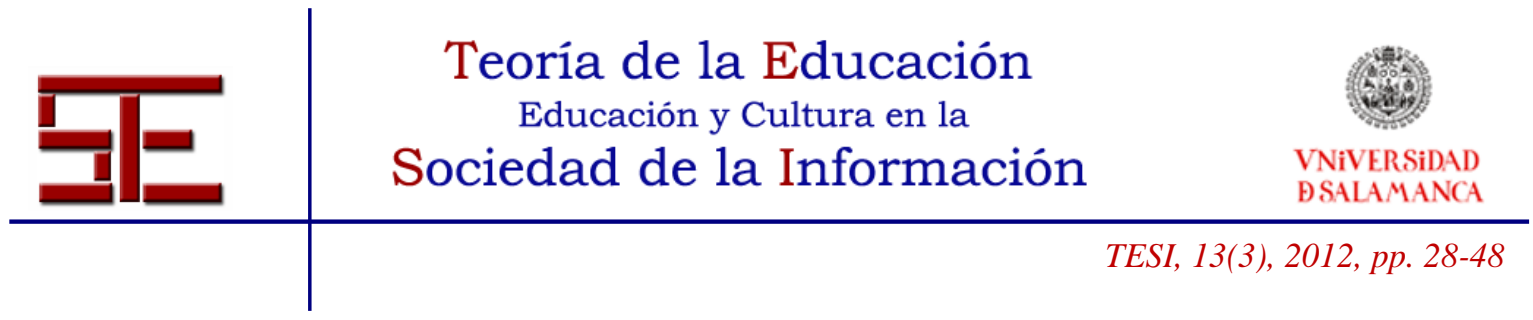

Araujo-Olivera, et al. (2005). Respeto, democracia, negociación de consenso. El caso de la formación cívica y ética en las escuelas secundarias de Morelos. Revista Mexicana de Investigación Educativa, 10(24),15-42.

Barba, B. y Matías, R. (2005). Desarrollo del juicio moral en la educación superior. Revista Mexicana de Investigación Educativa, 10 (24), 67-92.

Buxarrais, R. M. (2003). La formación del profesorado en Educación en Valores. Propuesta y materiales. Bilbao: Desclée de Brouwer.

Buxarrais, R. M., Martínez, M., Puig, J. y Trilla, J. (2001). La educación moral en primaria y secundaria. Una experiencia española. México: Progreso.

Camps, V. (1994). Los valores en la educación. Madrid: Alauda-Anaya.

Delors, J. et al. (1996). La educación encierra un tesoro. Informe a la UNESCO de la comisión internacional sobre educación del siglo XXI (compendio). Extraído el 30 de agosto de 2009, de : www.unesco.org/education/pdf/DELORS_S.PDF.

Ezpeleta, J. (2004). Innovaciones educativas. Reflexiones sobre los contextos en su implementación. Revista Mexicana de Investigación Educativa, 9 (21), 403-424.

Fierro, C. y Carbajal, P. (2003). Mirar la práctica docente desde los valores. México: GEDISA.

Gimeno, J. (1998). El currículo: una reflexión sobre la práctica. Madrid: Morata.

Hirsch, A. y Quesada, M. (2001). Educación y valores de los mexicanos. Las investigaciones realizadas en México de 1990 a 2001. Reencuentro, (31), 11-16.

Marchesi, A. (2008). Sobre el bienestar de los docentes. Competencias, emociones y valores. Madrid: Alianza Editorial.

Martínez, M. (2001). Educación y valores democráticos. En: OEI, La educación en valores en Iberoamérica. Papeles Iberoamericanos, 17-36.

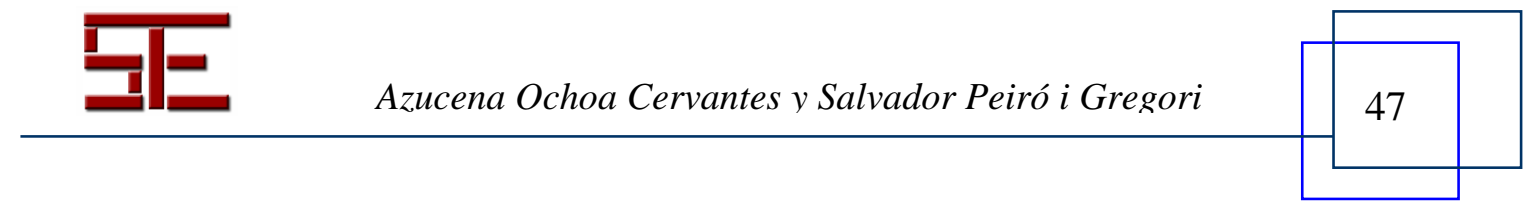




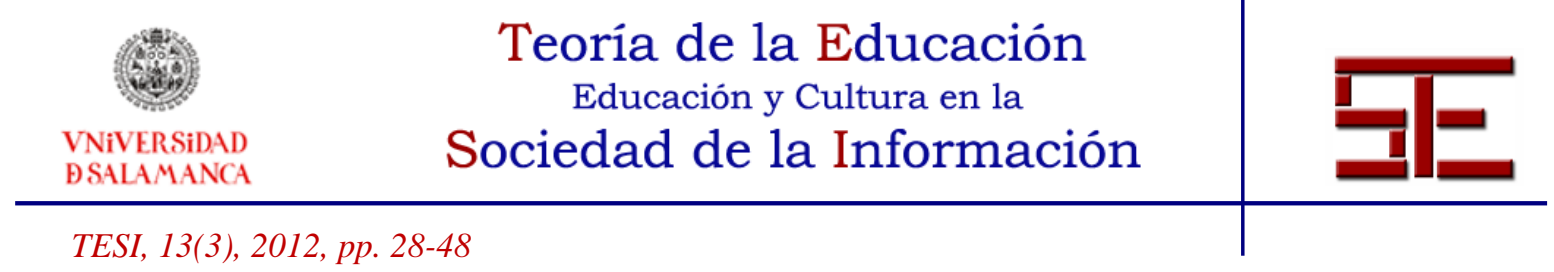

Matías, R. (2005). Desarrollo del juicio moral en bachilleres de Aguascalientes. Revista Mexicana de Investigación Educativa, 10 (24), pp. 43-66.

Ortega, P. y Mínguez, R. (2001). Los valores en la educación. Barcelona: Ariel.

Scmelkes, S. (1998). Educación y valores: hallazgos y necesidades de investigación.

Revista Educar, 4. Extraído el 30 de agosto del 2009, de: http://educar.jalisco.gob.mx/04/4indice.html.

UNESCO (1990). Declaración mundial de educación para todos "Satisfacción de necesidades de aprendizaje". Extraído el 29 de septiembre de 2009, de: www.unesco.cl/medios/biblioteca/documentos

- (2001). Cuadragésima sexta conferencia internacional de educación "Contenidos y estrategias de aprendizaje -problemas y soluciones-. Extraído el 2 de octubre de 2009, de:

www.ibe.unesco.org/Internacional/ICE/46espanol/46docs.htm.

Para citar el presente artículo puede utilizar la siguiente referencia:

Ochoa Cervantes, A. y Peiró i Gregori, S. (2012). El quehacer docente y la educación en valores. Revista Teoría de la Educación: Educación y Cultura en la Sociedad de la Información. 13(3), 28-48 [Fecha de consulta: dd/mm/aaaa].

http://campus.usal.es/ revistas_trabajo/index.php/revistatesi/article/view/9127/9356

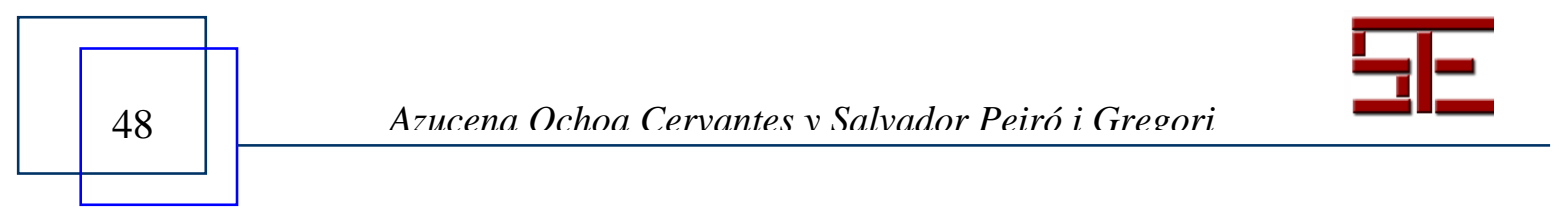

